Indian J. Anim. HIth. (2020), 59(1) : 45-49

DOI: $10.36062 /$ ijah.59.1.2020.45-49

\title{
STUDIES ON SOME PHYTOEXTRACTS FOR THEIR ANTIFUNGAL ACTIVITIES AGAINST MICROSPORUM CANIS
}

\author{
A. D. SINGH ${ }^{1}$, C. DEBNATH ${ }^{* 1}$, S. CHAUDHURI ${ }^{2}$, R. BISWAS ${ }^{1}$, R. BARUA ${ }^{1}$, \\ I. SAMANTA ${ }^{1}$ AND G. P. MANDAL ${ }^{3}$
}

\begin{abstract}
${ }^{1}$ Department of Veterinary Public Health, West Bengal University of Animal and Fishery Sciences, 37, K. B. Sarani, Kolkata-700 037, West Bengal, India

${ }^{2}$ Department of Veterinary Clinical Complex, West Bengal University of Animal and Fishery Sciences, 37, K. B. Sarani, Kolkata-700 037, West Bengal, India

${ }^{3}$ Department of Animal Nutrition, West Bengal University of Animal and Fishery Sciences, 37, K. B. Sarani, Kolkata-700 037, West Bengal, India
\end{abstract}

\begin{abstract}
Dermatophytes are responsible for a majority of superficial fungal infections. They are distinctive from other pathogenic fungi in their ability to use keratin as living. They can sustain in different ecosystems that added in their morphological and ecological range with high flexibility to changing environmental conditions. Lately, Microsporum canis has evolved as a resistant pathogen against several antifungals and has been in the focus of interest for causing outbreaks and epidemics in humans from domestic animals. The increasing evolution of resistance, therapeutic failures, and reduced number of available drugs stimulated to investigate therapeutic alternatives by using some commonly available plants empirically used for their antifungal properties. Likewise, the present study reports the in vitro antifungal efficacy of crude as well as fractionalized extracts with different solvents of Ficus racemosa leaves (L.), Cassia fistula $\mathbf{L}$. and Nerium oleander L. Antifungal activity was evaluated according to Clinical Laboratory Standards Institute (CLSI) protocol by determination of Minimum Inhibitory Concentration (MIC's) values on a clinical isolate of $M$. canis that showed resistance to some commonly used antifungals. All crude phyto-extracts except Nerium oleander L. effectively inhibited the growth of M. canis. The methanolic extract of Ficus racemosa L. and Cassia fistula L. completely inhibited the fungal growth at a concentration of $2 \mu \mathrm{g} / \mathrm{mL}$ and $8 \mu \mathrm{g} / \mathrm{mL}$ respectively. These two phyto-extracts proved to have significant antifungal activity against common antifungal resistant $M$. canis isolate. Further studies with the identified plant parts through in vivo studies and pin-point isolation of the active compound may prove beneficial as an effective alternative therapy for the pathogen.
\end{abstract}

Key words: Antifungal resistance, Ficus racemosa, Microsporum canis, Phytoextracts

Dermatophytes are specialized pathogenic fungi having the ability to invade keratinized structures viz. cornified skin layers, hair, and nails causing a superficial cutaneous infection called dermatophytoses/ringworm (de Hoog et al., 2017). They are distinctive from other pathogenic filamentous fungi in their ability to use keratin as their living. They can sustain in different ecosystems that added in their morphological and ecological range as well as high flexibility to changed environmental conditions (Singh et al., 2020). As per the new taxonomic tree, they are classified into nine clades based on multi-locus genetic analysis: Trichophyton, Microsporum, Epidermophyton, Arthroderma, Nannizzia, Lopophyton, Paraphyton, Ctenomyces and

\footnotetext{
"Corresponding Author
} 
Guarromyces against only three pathogenic genera Trichophyton, Microsporum and Epidermophyton used to be considered earlier (de Hoog et al., 2017). Microsporum canis, one of the zoonotic zoophilic dermatophyte can be isolated from dogs and cats with or without skin lesions (Singh et al., 2018; Moriello, 2019) and has recently found to develop resistance against various antifungals like fluconazole, amphotericin-B and terbinafine (Aneke et al., 2018). It produces arthroconidia which can remain infectious in the environment for as long as 12 to 24 months and this is the phase that plays crucial in the epidemiology of dermatophytoses through infection and re-infection (da-Cunha et al., 2019).

Fungi are one of the most neglected pathogens as demonstrated by the fact that amphotericin $\mathrm{B}$, a polyene antibiotic discovered as long ago as 1956, is still used as a "gold standard" for antifungal therapy (Faustino and Pinheiro, 2020). At the same time, the development of effective antifungal drugs is lagging so much that the future pipeline has been dry (Perfect, 2017). Over the last three decades, rampant uses of antifungals have led to the evolution of resistance and failures in the treatment which have accentuated the serious problem of antifungal resistance (Ortiz and Torres, 2018). Also, most of the clinically used antifungals have various drawbacks concerning toxicity, efficacy and cost (Graninger et al., 2019).

In October 2013, World Health Organization (WHO) announced the 2014-2023 traditional medicine policy to offer guidance for countries to elaborate regulation, effective governance, and to integrate traditional medicine practices in modern medicine (WHO, 2013). Plant-derived bio-active constituents comprise safer and more effective substitutes for synthetically produced antimicrobial agents (Ndlovu et al., 2019), and resistance against them is rarely observed (Warnke et al., 2009). Also, the capacity of natural products to act on multiple cell targets is key to combat resistant microorganisms that do not respond to conventional therapies (Lopes et al., 2017). With this backdrop, the present study was aimed to determine the in vitro antifungal efficacy of crude and fractionalized purified extract of three empirically used plants namely Ficus racemosa L., Cassia fistula L. and Nerium oleander L. against common-antifungal-resistant $M$. canis isolated from asymptomatic pet kitten.

\section{MATERIALS AND METHODS}

Plant materials used: Leaves of the Ficus racemosa, Cassia fistula, and Nerium oleander plants were collected from Kolkata, West Bengal from a period of February 2020 to April 2020. Primarily, the plants which were reported to have some antibacterial or antifungal properties were selected. Secondly, their availability throughout the year was judged and parts having regeneration capacity to make the study sustainable were considered. Initially, the collected leaves were rinsed with distilled water to remove soil and other impurities and then dried in a cool and dark place for further processing.

\section{Preparation of plant extract (crude extract):} The dried leaves of the selected plants were crushed in a grinder to make a powder. For hot crude extract, $100 \mathrm{~g}$ of dried powder was weighed and extracted with $250 \mathrm{~mL}$ of ethanol in a soxhlet apparatus at $40^{\circ} \mathrm{C}$ for $12-14$ cycles and for cold crude extract the same amount was kept in shaker incubator for four to five days or until the extraction was completed (Lopez-Bascon and de-Castro, 2020). The final recovered extract was passed through a rotary evaporator to remove the solvent and the extract was dried under vacuum and stored in an amber-colored bottle at $4^{\circ} \mathrm{C}$ for further use. Both the extracts (hot and cold) of each plant were subjected to antifungal sensitivity testing (AFST) using the Clinical Standards Laboratory Institute (CLSI) guidelines (NCCLS, 2002).

Preparation of fractional extraction: Out of a total of six crude extracts, the best two crude extracts showing lowest MIC value were subjected to different solvent extractions as per the 
phytochemical property of extract to isolate most suitable solvent fraction(s) containing bioactive components responsible for antifungal activity in a column chromatography viz. butanol, hexane, chloroform and methanol according to the protocol suggested by Coskun (2016).

Fungal isolate selection and inoculums preparation: The selected clinical isolate of M. canis (Fig. 1) detected from asymptomatic pet kitten in this present study, was confirmed by using both conventional cultural and molecular methods (Singh et al., 2018). The isolate was also showing in vitro resistance to some common antifungals like amphotericinB $(\mathrm{MIC}=32 \mu \mathrm{g} / \mathrm{mL})$, fluconazole $(\mathrm{MIC}=64 \mu \mathrm{g}$ / $\mathrm{mL}$ ) and itraconazole (MIC $=32 \mu \mathrm{g} / \mathrm{mL})$. The gene sequence of the isolate has been submitted to the GeneBank ${ }^{\circledR}$ database under accession number MT270284.

The selected isolate was further sub-cultured on Potato Dextrose Agar (PDA) for 7-10 days at $28^{\circ} \mathrm{C}$. To prepare the inoculum for the study, sterile normal saline solution ( $85 \%$ ) was added to slants, and cultures were gently scrubbed with a sterile loop to dislodge conidia; thereafter vortexed and supernatant was collected. The optical density of the supernatant was read by double beamed UV spectrophotometer at $530 \mathrm{~nm}$, adjusted to the transmittance of $60-70 \%$ and diluted with Roswell Park Memorial Institute (RPMI) 1640 medium to acquire final inoculums concentration of 0.4 to 5 $\times 10^{4}$ cells $/ \mathrm{mL}$ (Singh et al., 2018).
Determination of Minimum inhibitory concentration (MIC): MIC values were determined by the broth micro-dilution assay method described by CLSI protocols approved standard M38-A (NCCLS, 2002). Dried extracts collected from the plants were diluted in $100 \%$ Dimethyl sulfoxide (DMSO) to the strength of $1 \mathrm{mg} / \mathrm{mL}$ to make a standard solution. In sterile microdilution plates $\left(\right.$ Tarsons ${ }^{\circledR}$ ), columns 1 and 12 were filled with $200 \mu \mathrm{L}$ each of plant extract and fungal inoculum to serve as a negative and positive growth control respectively. Columns 2 to 11 were filled with both fungal inoculum and serially diluted plant extract ( $100 \mu \mathrm{L}$ each) so those final concentrations ranged from 64 to $0.125 \mu \mathrm{g} /$ $\mathrm{mL}$. The microdilution plates were then incubated at $28^{\circ} \mathrm{C}$ and were interpreted visually after 3 days of incubation. The well where the lowest concentration of the extract was completely inhibiting the visual growth of the dermatophyte was defined as the MIC value of that extract.

\section{RESULTS}

The MIC values of hot crude extract of leaves of Ficus racemosa, Cassia fistula and Nerium oleander were 4,16 and $32 \mu \mathrm{g} / \mathrm{mL}$ respectively. None of the cold crude extracts showed an inhibitory effect against $M$. canis isolate (Table 1). The lowest MIC was seen in a methanolic fraction of hot crude extract of Ficus racemosa (FRM) and Cassia fistula (CFM) which was recorded as 2 and $8 \mu \mathrm{g} / \mathrm{mL}$ respectively (Fig. 2). The other fractions with butane (B), hexane $(\mathrm{H})$ and chloroform $(\mathrm{C})$ were also produced the weak antifungal effects.

Table 1. Showing Minimum inhibitory concentration values of selected crude phytoextracts (hot and cold) against Microsporum canis isolate

\begin{tabular}{lcc}
\hline Selected phytoextracts & $\begin{array}{c}\text { Crude } \\
\text { extracts }\end{array}$ & $\begin{array}{c}\text { Minimum inhibitory concentration (MIC) } \\
(\boldsymbol{\mu g} / \mathbf{m L})\end{array}$ \\
\hline Ficus racemosa Leaves (L.) & Hot & 4 \\
& Cold & 32 \\
Cassia Fistula L. & Hot & 16 \\
& Cold & 64 \\
Nerium oleander L. & Hot & 32 \\
& Cold & 64 \\
\hline
\end{tabular}


Indian Journal of Animal Health, June, 2020

Antifungal effect of phyto-extracts

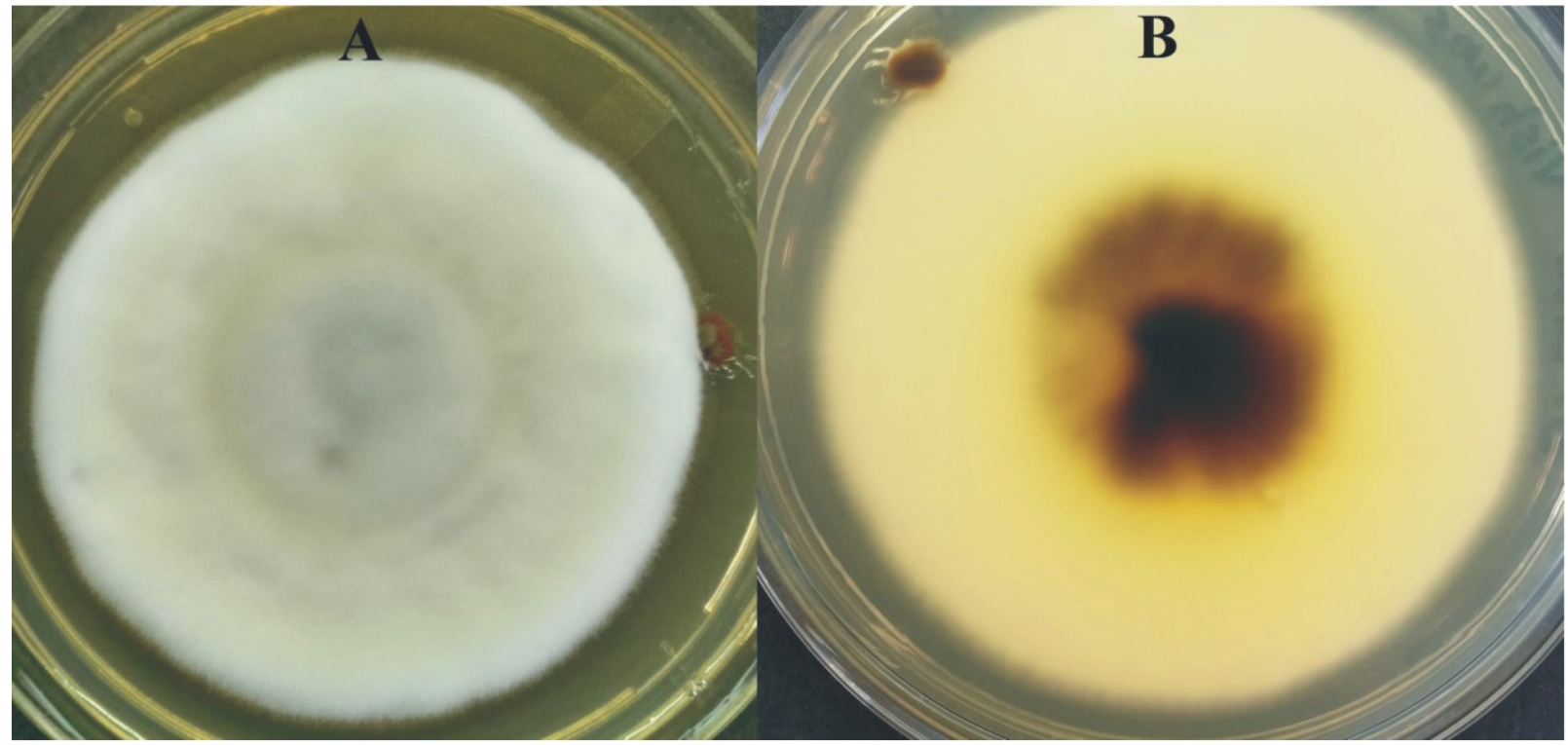

Fig. 1. Obverse (A) and Reverse side (B) of Microsporum canis isolate on Sabouraud Dextrose Agar (SDA) plate

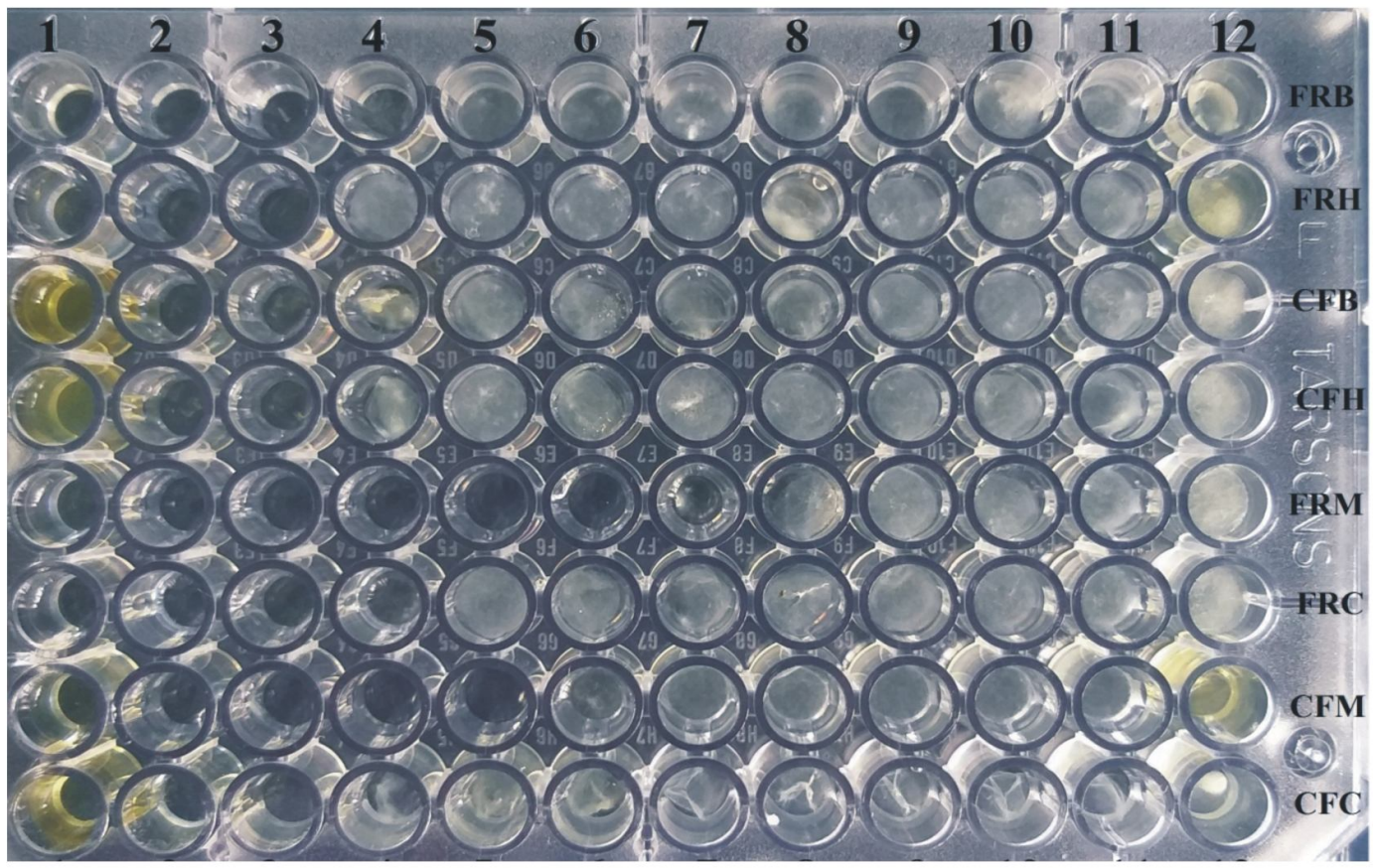

Fig. 2. Antifungal sensitivity testing (AFST) against hot crude extract Ficus racemosa (FR) and Cassia fistula (CF). (Starting two alphabets represent plant name and the last alphabet represent the fraction name; B-Butane, H-Hexane, M-Methanol, and C-Chloroform) 


\section{DISCUSSION}

The present study revealed the methanolic extract of Ficus racemosa to have significant antifungal activity against $M$. canis isolate. This finding is in the same line as reported by Singh and Vidyasagar (2015) where antifungal activity (MIC $=5 \mu \mathrm{g} / \mathrm{mL}$ ) of the same fraction was observed against $T$. rubrum isolates. In a similar study by Phongpaichit et al. (2004) reported superior antifungal properties of the methanolic fraction of Cassia fistula L. against T. rubrum and $M$. gypseum isolates having a MIC of 8 and $4 \mu \mathrm{g} / \mathrm{mL}$ respectively. Again, Kadhim et al., 2016 reported antifungal activity of methanolic fraction from fruits of Cassia fistula plant against $M$. canis isolates ( $\mathrm{MIC}=4 \mu \mathrm{g} / \mathrm{mL})$.

Based on the results obtained, it may be

\section{REFERENCES}

Aneke CI, Otranto D and Cafarchia C, 2018. Therapy and antifungal susceptibility profile of Microsporum canis. J Fungi, 4(3): 107

Coskun O, 2016. Separation techniques: chromatography. Northern clinics of Istanbul, 3(2): 156

da-Cunha MM, Capote-Bonato F, Capoci IRG, Bonato DV, Ghizzi LG et al., 2019. Epidemiological investigation and molecular typing of dermatophytosis caused by Microsporum canis in dogs and cats. Prev Vet Med, 167: 39-45

de Hoog GS, Dukik K, Monod M, Packeu A, Stubbe D et al., 2017. Toward a novel multilocus phylogenetic taxonomy for dermatophytes. Mycopathologia, 182(1-2): 5-31

Faustino C and Pinheiro L, 2020. Lipid systems for the delivery of amphotericin $\mathrm{B}$ in antifungal therapy. Pharmaceutics, 12(1): 29

Graninger W, Diab-Elschahawi M and Presterl E, 2019. Antifungal Agents. In Clinically Relevant Mycoses. Springer, pp31-42

Kadhim MJ, Mohammed GJ and Hameed IH, 2016. In vitro antibacterial, antifungal and phytochemical analysis of methanolic extract of fruit Cassia concluded that the leaves of the plants' Ficus racemosa and Cassia fistula may prove useful as a new and potent source of the antifungal agent against the targeted dermatophyte. Further research with the identified plant parts through in vivo studies and pinpoint isolation of the active compound may prove beneficial to find out an effective alternative therapy for the pathogen.

Conflict of interest: The authors have no conflict of interest to declare.

\section{ACKNOWLEDGEMENTS}

The authors express their sincere gratitude to Indian Council of Agricultural Research (ICAR), New Delhi, India for providing the necessary funds under 'Outreach Programme on Zoonotic Diseases'.

fistula. Orient J Chem, 32(3): 1329-1346

Lopes G, Pinto E and Salgueiro L, 2017. Natural products: An alternative to conventional therapy for dermatophytosis?. Mycopathologia, 182(12): $143-167$

Lopez-Bascon MA and de-Castro ML, 2020. Soxhlet Extraction. In Liquid-Phase Extraction. Elsevier, pp327-354

Moriello K, 2019. Dermatophytosis in cats and dogs: A practical guide to diagnosis and treatment. In Practice, 41(4): 138-147

NCCLS, 2002. Reference method for broth dilution antifungal susceptibility testing of filamentous fungi. Approved standard M38-A. National Committee for Clinical Laboratory Standards, Wayne, $\mathrm{Pa}$

Ndlovu B, Africa C, Klaasen J and Rahiman F, 2019. The use of South African medicinal plants in the treatment of fungal skin infections: A systematic review. Australasian Med J, 12(8): 246-254

Ortiz C and Torres R, 2018. Antifungal resistance and its evolution: An increasing concern. Adv Biotechnol Microbiol, 10(1): 1-7 


\section{Antifungal effect of phyto-extracts}

Perfect JR, 2017. The antifungal pipeline: A reality check. Nat Rev Drug Discov, 16(9): 603

Phongpaichit S, Pujenjob N, Rukachaisirikul V and Ongsakul M, 2004. Antifungal activity from leaf extracts of Cassia alata L., Cassia fistula L. and Cassia tora L. Songklanakarin. J Sci Technol, 26(5): 741-748

Singh A, Debnath C, Banerjee A, Batabyal K, Roy B et al., 2018. Effects of propylene glycol and magnesium chloride against dermatophytes isolated from companion animals. Indian $\mathrm{J}$ Anim Hlth, 57(2): 213-218

Singh AD, Debnath C, Biswas R and Barua R, 2020. Analysis of putative virulence-associated factors of Nannizzia gypsea isolated from pet dogs. J Entomol Zool Stud, 8(2): 1931-1935

Singh PS and Vidyasagar GM, 2015. Antifungal screening of 61 folkloric medicinal plant extracts against dermatophytic fungi Trichophyton rubrum. J Appl Pharm Sci, 5(5): 38-40

Warnke PH, Becker ST, Podschun R, Sivananthan S, Springer IN et al., 2009. The battle against multiresistant strains: renaissance of antimicrobial essential oils as a promising force to fight hospital-acquired infections. J Cranio Maxill Surg, 37(7): 392-397

WHO, 2013. WHO Traditional Medicine Strategy, 2014 2023. Geneva: World Health Organization 